\title{
DEMOCRACIA Y PRAXIS EN EL JOVEN HABERMAS
}

BERNAT RIUTORT SERRA *

Eltalante de los estudiantes radicales de la República Federal Alemana a finales de los cincuenta tiene en el joven Habermas una de sus voces paradigmáticas: expresa el malestar que experimentan en el ambiente de silencios respecto del pasado y las aspiraciones a una democracia sin inhibiciones, levantando la represión colectiva sobre el pasado nazi, como condición de una asunción pública de la nueva democracia.

En este contexto el marxismo crítico y no leninista de los frankfurtianos retornados del exilio se convierte en punto de referencia para la filosofía radical de los jóvenes pero, el diagnóstico de Adornoy Horkheimer sobre los caminos sin salida de la modernidad-marcado por el profundo pesimismo de la generación de judios de izquierda que padecieron el holocausto- no sintoniza con la prosperidad del nuevo Estado Social de Derecho. Para la nueva generación de radicales la democracia es promesa emancipatoria. Según el joven Habermas el "curso de la historia no es racional según leyes inmanentes. Son los mecanismos de nuestra sociedad los que nos fuerzan a restringir cada vez más sus irracionalidades a tenor de las fuerzas sociales existentes y de las posibilidades que esas fuerzas abren objetivamente. Aunque lahistoria no tiene 'ningún sentido', síque nos desafía en la práctica a intentar prescribirle el camino de una eliminación progresiva del sin sentido".(1)

La filosofía crítica del joven Habermas tiene como eje la realización de la democraciay las contradicciones que ésta presenta en el capitalismo organizado. Tal proyecto se presenta como una revisión de la dialéctica de la ilustración focalizada en la publicidad política. La crítica, desde la razón práctica, de la formación de la publicidad política y su transformación se apunta como alternativa.

\footnotetext{
- Departamento de Filosofía, Universidad de las Islas Baleares, España.
} 


\section{Primera reflexión sobre la democracia}

La literatura politológica del momento estiliza dos concepciones opuestas de la democracia; una concibe la democracia bajo la analogía del equilibrio de mercado; la otra toma como eje reflexivo la emancipación. Habermas realiza su análisis de la primera desde su interpretación de la segunda.(2)

a) La democracia como mercado se ocupa del sistema de reglas que permite la formación de decisiones políticas por parte de élites que se turnan en el gobierno, respetando la ley de la mayoria. El resultado de esta alternancia ha de ser la optimización de las decisiones, facilitada por la competencia electoral entre partidos, con vistas a los rendimientos del sistema económico.

Elidealde la soberanía popular es un dispositivo heredado de la legitimación ante las masas que disfrutan de un régimen de libertades y están interesadas por el consumo privado y los servicios estatales. La cantidad y calidad de la participación es mediatizada y dosificada por partidos, instituciones estatales y medios de comunicación de modo que oscileentre umbrales funcionales al sistema; demasiada participación pone en peligro la necesaria separación del gobierno respecto de los gobernados; cuando la participación baja hasta determinadas cuotas pueden aparecer deficiencias legitimatorias en el sistema de dominación.

b) La democracia como forma de emancipación humana sólo puede realizarse por medio de la autodeterminación de individuos y comunidades. Para Habermas, "la realidad constitucional del estado burgués siempre ha estado en contradicción con la idea de democracia que constituye su origen, si bien siempre se ha podido mantener la contradicción en el interior del marco constitucional".(3) La libertad se realiza participando en la formación de la voluntad colectiva por parte de todos los ciudadanos. La democracia radical es política y social, formay contenido se conjugan en la misma dinámica transformadora.

Idealmente, la constitución liberal supone una sociedad de ciudadanos que a su vez son pequeños productores mercantiles que disponen de una distribución más o menos uniforme de la propiedad. Dicha sociedad jamás ha existido, no obstante, en ciertos lugares y momentos de la transición del feudalismo al capitalismo pareció el ideal a realizar.

Realmente, lanueva sociedad civilburguesa se estructura básicamente en torno a la relación de clases entre capitalistas y trabajadores. La separación del Estado liberaly sociedad civil tiene por función garantizar la dinámica autónoma del mercado que reproduce ampliadamente la relación delcapital. La democracia censitaria en una sociedad clasista sólo representa a las minorias dominantes. El Estado liberal asegura, de una parte la integridad y funcionamiento del mercado, de otra armoniza las relaciones internas entre los burgueses, opuestos entre ellos en relación a sus intereses privados.

La "cuestión social" emerge como confrontación directa, económica y política de clases. Marginadas de la representación censitaria las masas obreras van 
organizando la "nación" dentro de la nación, a través de sus embriones de partidos, asociaciones informales, sindicatos, etc. Las luchas de clases con diversos ritmos y suertes van imponiendo el reconocimiento del sufragio universal, modificando el sistema de representación política; se institucionalizan los partidos y sindicatos de clase. Se transforma la democracia burguesa en democracia representativa.

El desarrollo del capitalismo imperialista a partir del último cuarto del siglo XIX y las crisis económicas impelen alEstado, "guardián noctumo" delorden establecido, a desenvolver nuevas funciones destinadas a sostener y regular el proceso de producción en sus fallas. El Estado liberal se transforma en Estado Interventor. Desde entonces crece la interdependencia entre Estado y sociedad civil sin que la separación entre ambos desaparezca, tal proceso lleva aparejado el surgimiento de un terreno intermedio, ambivalente.

Jurídicamente, el sistema de derecho privado clásico disuelve sus fronteras sin que pueda reducirse a derecho público, y este último se desarrolla con crecientes elementos de privatización. Las intervenciones sistemáticas del Estado en la sociedad civil requieren la ampliación del catálogo de derechos; la formulación negativa de los derechos liberales clásicos se amplía con la legislación positiva del Estado Social, invocando criterios de justicia.

Después de la segunda Guerra Mundial las tendencias señaladas se acentúan. La "zona neutra" de mediación se convierte en espacio preparlamentario, con carácter privado, donde partidos y grupos de presión actúan. Los actores de la politica juegan sus cartas sustrayéndolas en gran medida del control público. En el intervalo los partidos obreros de masas se han transformado en burocracias profesionalizadas integradas en el juego de la mediatización interna al sistema.

Los grandes partidos burocráticos al conseguir una mayoria de gobiemo, no sólo unifican su actuación partidaria bajo una estricta disciplina en manos de las cúpulas, sino que también unifican la acción del ejecutivo y el legislativo, bajo la dirección del primero. La mayor parte de la labor del legislativo se limita a modificaciones de detalle sobre proyectos presentados por el ejecutivo y elaborados por la burocracia estatal a su servicio.

El ciudadano privado, fuera de una organización política o un grupo de presión es despolitizado, es un sujeto de derechos politicamente pasivo. Los partidos y grupos de poder se dirigen a él a través de la propaganda y el marketing político, solicitándole el consenso pasivo. La opinión pública se forma a través de los grandes medios de comunicación de masas en manos de unos pocos oligopolios que controlan la información y difunden la representación estandarizada que los partidos llevan a cabo en la escena política, básicamente articuladora del consenso en torno al sistema, y sólo secundariamente confrontadora de programas políticos contrapuestos que, con el tiempo, se han hecho más generales e indiferenciados.

La cultura plebeya ha entrado en los canales de la cultura consumista. El ciudadano privado se halla emplazado ante el Estado social como cliente que intenta recibir prestaciones, no como miembro de su clase, provocando un efecto de 
corporativización de los sectores aventajados de èsta que intentan recibir y consolidar sus privilegios. Los grupos de interés sustraen sus negocios a la publicidad y participación, su poder, no obstante, se vale de medios de influencia públicos bajo su control.

El análisis crítico de Habermas, realizado desde la concepción emancipatoria, presenta una serie de alternativas programáticas: la participación de los ciudadanos debe ser real; la opinión pública ha de formarse horizontalmente de manera dialogante; el control público de los grandes medios de producción es clave para que no se formen grandes poderes prepolíticos sustraídos a la publicidad; la esfera de planificación social del Estado ha de ser controlada verdaderamente por el público y no por instancias de mediatización prepolíticas; los sindicatos y partidos de masas han de orientar su acción en función de principios universalistas y no corporativistas encubiertos.

La publicidad de todas las cuestiones politicas sociales, económicas y culturales del Estado Social, la participación horizontaly la simetría de todos los ciudadanos a la hora de configurar las decisiones se convierten en la clave de la concepción democrática de Habermas. La crítica al Estado Social no se hace para destruirlo desde una lucha externa contra él, o para reemplazarlo por una forma de Estado proletario, como plantea el marxismo izquierdista y el leninismo, sino para transformarlo a partir de su radicalización democrática. Desde esta perspectiva concibe el desarrollo del socialismo democrático, con control público y no burocrático de los grandes medios de producción.

Habermas hace su análisis de la democracia representativa pensando en las limitaciones que ésta presenta en la República Federal en la época de Adenauer. Acierta en su diagnóstico crítico y plantea unos principios democrático radicales para la izquierda que no son ni el consejismo ni el leninismo.

La concepción de lo que es una sociedad capitalista compleja y la valoración del principio democrático le inducen a buscar alternativas emancipatorias a partir del nivel civilizatorio y democrático alcanzado. El marxismo radical-democrático del joven Habermas no es un retroceso a las concepciones radical-democráticas del joven Marx. Lo que de ellas hay en la concepción participativa y emancipatoria de Habermas es reinterpretado con el punto de mira puesto en una sociedad con indudables logros civilizatorios, a pesar de las muchas críticas y atrocidades que tiene a su cargo.

\section{Publicidad burguesa y democracia}

Habermas construye unalaboriosa genealogía del significado de lapublicidad en la historia occidental. Público y privado son categorias que se remontan a la antigüedad griega y nos han llegado a través de la versión romana. La publicidad feudal es juridictio, no hay verdadera separación de esferas. Dichas formas de publicidad y privacidad se diferencian de las actuales. 
Lapublicidad representativadel período de transición del feudalismo al capitalismo se transforma en publicidad burguesa separando los ámbitos público y privado, antes confundidos en los escalones de las jerarquías feudales. La Reforma separa la Iglesia del Estado, privatizando la conciencia religiosa. El Estado desarrolla la burocracia, la fiscalidad y la legalidad, el poder público en sentido estricto. Las revoluciones burguesas convierten las antiguas Cortes estamentales en Parlamentos burgueses. La actividad privada mercantil, financiera e industrial se convierte en asunto privado, al depender de las nuevas relaciones de producción capitalistas; el Estado, como poder público, vigilará su normal desenvolvimiento. La nueva actividad económica fuera delámbito familiar-es privada, si bien las consecuencias de dicha actividad son públicas; es economía política. El ámbito familiar, personal y amoroso, es el centro de la privacidad por excelencia. Las personas privadas como destinatarias de las intervenciones del Estado forman el público.

Entre loprivadoy lo público en sentido estricto aparece unazona de intermediación que surge de lo privado y se proyecta hacia el Estado, es la publicidad burguesa. La burguesía es el sostén de la nueva publicidad; se entiende a símisma como público ilustrado de lectores de, periódicos, literatura, cartas, panfletos, noticias oficiales, etc. Los burgueses frecuentan lugares de nueva creación que proliferan en la ciudad, salones, casas de té, ligas, teatros, etc. Tanto la lectura como los nuevos círculos favorecen un ámbito de comunicación entre personas individuales independientemente de su origen y condición. La racionalidad de los argumentos obtenidos a través de su discusión pública es la nueva fuente ideal de autoridad.

El poder público se legitima ante la opinión pública a través del raciocinio de las personas privadas, los burgueses -el pueblo está excluido-. En Inglaterra, la oposición entre Parlamento y country, corona y chancelors, es sustituida por la lucha institucionalizada entre dos grandes partidos que defienden los grandes intereses de las clases que componen el bloque dominante. En Francia con la Revolución aparece de golpe y de manera más consciente lo que en Inglaterra había costado siglo y medio de luchas y evolución; la Déclaration des Droits de l'home et du Citoyen y la Constitución.

La institución familiar burguesa es el crisol de la nueva subjetividad, lugar de intimidad e ilustración a la vez que del patrimonio y la herencia burguesas. Las relaciones amorosas entre esposos, parecen fundamentar las virtudes de la nueva subjetividad; "libertad volitiva, comunidad amorosa e instrucción dan lugar a una idea de humanidad que se entiende como inherente a ella y que, ciertamente, le fija por vez primera y de un modo absoluto su posición; la emancipación".(4)

Habermas sabe que el pueblo no participa de este modelo de ilustración, la ilustración burguesa no es la emancipación humana, no obstante, el nuevo ideal de sujeto autónomo adquiere la categoría de logro evolutivo para la humanidad; representa un hito en su historia al ofrecer un ideal a seguir. Es una idealización que destaca determinados caracteres e ignora otros, reales e igualmente importantes. El fin de esta maniobra metodológica es la obtención de un ideal de sujeto racional 
autónomo moralmente determinado que en sus relaciones comunicativas con otros forma el público. Lo que le interesa es la potencialidad contrafáctica de tal estilización. Por otra parte, posiblemente tengan razón los numerosos críticos del público burgués de Habermas al resaltar las deficiencias historiográficas de la narración.

Habermas sabe que en la familia burguesa, detrás de la apariencia de libertad se encubre la relación autoritaria del pater, junto al vínculo afectivo se instala la represión sexual y, el interés patrimonial y hereditario. La aparente comunidad ética ideal, realmente, cumple la función social de reproducción de los miembros de la clase explotadora. Lailustración de las personas privadas en el seno de la familia no es sólo universalista, responde al interés burgués. Sin embargo, los ideales de emancipación humana aparecidos en su seno no son mera ideología, ofrecen por primeravez un ideal civil de humanidad en elcual todos los individuos son igualmente dignos. El burgués también es hombre. La familia es, por un lado, agente social en el mercado, forma parte de la segmentación clasista y, por el otro, en su ideal de ilustración anticipa la emancipación. El pater familiaburgués es propietarioy hombre, en la sociedad puede actuar como propietario, respondiendo a sus intereses privados, o como sujeto racional dialógico, desarrollando el camino emancipatorio.

La llustración, a pesar de las críticas de los frankfurtianos clásicos, es interpretada positivamente: La intersubjetividad deldiscurrir en público de los sujetos autónomos aúna a la colectividad en un consenso racional, no impuesto, asumido como resultante de la participación de los sujetos autónomos. El nuevo sujeto autónomo idealizado parece poseer competencias no sólo técnico-instrumentales, como destacaba el modelo de razón desarrollado por Adorno y Horkeimer, sino también intersubjetivas, comunicativas, dirá en estudios posteriores.

La subjetividad desarrollada en el crisol familiar se proyecta en los ámbitos microsociales de relación, los nuevos círculos de relación y la publicidad burguesa literaria, idealmente dialógicos, concebidos conjuntamente, forman el público ilustrado; el gran público fiscalizador del Estado. El planteamiento habermasiano de la publicidad burguesa sugiere la continuidad entre el nivel micro social y el nivel estructural de relaciones sociales -contrafácticamente interpretado-comomodelo de racionalidad dialógica.

Habermas tiene una visión kantiana de la publicidad burguesa. Para Kant, las personas privadas, políticamente raciocinantes, se enfrentan a la dominación absolutista. La opinión pública tiene que racionalizar la política desde la moral. El público no coaccionado y en proceso de ilustración se emancipa a si mismo. La publicidad es un principio de ordenación jurídica y un método de ilustración que media la política y la moral. La "sociable insociabilidad" -automatismo de armonización de oposiciones resultante de la competencia entre muchos, ya sea en el mercado o en el debate público- garantiza que la humanidad progresa. El bourgois y el homme, el propietario privado y el sujeto autónomo, con el tiempo han de converger, de manera que la moralidad del hombre propietario dé soporte, a través del público ilustrado, a 
la legalidad, es decir, fundamenta la existencia del citoyen que toma parte en las responsabilidades públicas a través de la votación.

Marx critica esta concepción. De una parte, la sociedad civil burguesa deshizo la sociedad en sus partes constitutivas, los individuos, los elementos materiales y los elementos espirituales, aboliendo su carácter político. De otra parte, la sociedad política es fruto de la recomposición y concentración de los asuntos generales en el Estado. La crítica maxiana de la sociedad civil burguesa localiza el elemento clave de la nueva sociedad en la relación de las clases. La forma del contrato de trabajo en la que el capitalista posee los medios de producción y el dinero con el que compra la fuerza de trabajo es presentada por el pensamiento liberal como libre y neutral, encubriendo la relación de poder contractual favorable a los primeros y desfavorable a los segundos. La idealización de la igualdad de los individuos en la sociedad civil que constituye el público raciocinante es denunciada como ideología.

La división en clases de la sociedad capitalista imposibilita a la mayoría de la población ser, a la vez, propietarios y hombres. La propiedad privada de los medios deproduccióny laconstitución universalista de un público raciocinante presentan una contradicción no resoluble si no se modifican las relaciones sobre las que se constituye. En Marx hay un salto entre el nivel micro social y el nivel estructural de la sociedad, es otro orden de articulación de las relaciones. En la sociedad capitalista este orden se establece en torno a la relación de clases, mientras que el modelo de publicidad kantiano parte de un ideal emancipatorio surgido de las relaciones microsociales burguesas que se extiende al público ilustrado. Desde el enfoque marxiano el público ilustrado kantiano no puede ser el motor de la emancipación social, pues no hay continuidad entre los niveles de articulación micro social y estructural.

En Marx, la clase trabajadora ha de ser sujeto de la publicidad ampliada, a través de la participación y la defensa de sus objetivos autónomos, transformando en este proceso la constitución de las relaciones de propiedad. Las nuevas relaciones de poder han de penetrar las relaciones de producción, socializándolas. La idea liberal de una publicidad políticamente activa ha encontrado su concepción socialista. "Las personas privadas serán personas privadas de un público antes bien que el público un público de personas privadas. En lugar de la identidad entre bourgois y homme, entre propietario privado y hombre aparecerá la identidad entre citoyeny homme; la libertad del hombre privado se determinará según el rol de los hombres como ciudadanos sociales".(5)

El ideal de sujeto moral y político habermasiano, en el que coinciden hombre y ciudadano, no se relaciona históricamente con la alienación, la eticidad práctica y la emancipación. No se establecen conexiones con el motor histórico marxiano, la lucha de clases, o un/os equivalente/s. Habermas adopta un modelo kantiano de razón práctica. La democracia socialista de individuos raciocinantes es aclasista y ahistórica, es un "reino de los fines" político-moral, no es política activa, y tiene en germen una consecuencia que desarrollará veinte años más tarde, "el fin de la utopía 
del trabajo" y la necesidad de la "utopía de la comunicación".(6) La estilización del modelo socialista democrático en el cual el hombre y el ciudadano coinciden, y en el que la propiedad de los medios de producción está en manos de los individuos asociados que forman el público, y no de la burocracia estatal, no encuentra una mediación con la praxis. El modelo de público liberal concebido contrafácticamente y ampliado a través de la crítica manxiana del público burgués, esboza lo que será la comunidad ideal de diálogo de su posterior teoría de la razón comunicativa, un ideal de socialismo democrático basado en un ideal de comunicación.

La transformaciones que el capitalismo y el Estado liberal experimentan después de Marx cambian el contexto de la discusión. El capitalismo entra en un período de recomposición del modelo de acumulación de capital y del papel del Estado. Se inicia un proceso de centralización y concentración de capital que oligopoliza sectores avanzados de la producción, el intercambio y la financiación, iniciando la fase imperialista del capitalismo. Por otra parte, los sindicatos y los partidos obreros ganan zonas de presencia pública, tienen que ser reconocidos con el fin de realimentar la legitimidad del sistema y estabilizar el potente conflicto de clases. El intervencionismo estatal resulta de la confluencia de las citadas tendencias. La "progresiva estatalización de la sociedad paralela a una socialización del Estado comienza paulatinamente a destruir la base de la publicidad burguesa: la separación entre Estado y sociedad".(7) Comienza un cambio estructural de la publicidad burguesa.

La privacidad burguesa reduce sus funciones, asumidas ahora por grandes organizaciones empresariales y estatales. La organización salarial y del trabajo se convierte en impersonal; se realiza a través de mediadores técnicos, controladores y ejecutivos en la gran empresa privada y, a través de una compleja estructura empresarial o funcionarial en la pública. Cada vez es másirrelevante para la dinámica de la acumulación del capital la decisión autónoma del pequeño propietario. Las pautas de acumulación las define la gran empresa. El capital privado se organiza en forma de sociedades anónimas diferenciando entre quienes controlan los destinos del capital y quienes poseen títulos de propiedad y reciben dividendos por ellos.

Las esferas familiar y profesional escinden sus funciones; la una es reserva de privacidad, desligada de la producción y centrada en el consumo de mercancías necesarias a la realización del capital; la otra, fuera del círculo familiar, adquiere un carácter casi público. El rol de la familia burguesa se ha desplazado a la periferia de lo público. Las funciones asistenciales de la familia -salud, vejez, educación- son asumidas cada vez más por el Estado de Bienestar. Las figuras familiares pierden atribuciones y entran en crisis.

Aldesaparecerelespacio reflexivo, elindividualismo fomentalapseudoprivacidad, la anonimidad y el consumismo manipulativo de las pulsiones individuales -a través de la propaganda y el estímulo subliminal-. La moderna metrópolis de asfalto sustituye la ciudad-comunidad por un conglomerado funcional de espacios en los cuales la calle y la plaza se convierten en vía rápida y aparcamiento, la casa y la 
vecindad en alojamiento y barrio dormitorio. La distancia reflexiva que permitía la comunicación dialógica, fundamento del público, se convierte en agregación de individuos y masas que circulan, se forman y se desintegran rápidamente. A la enorme concentración de medios de comunicación corresponde una menor comunicación entre sujetos autónomos. La privacidad es sustituida por el individualismo, la ilustración por lamanipulación técnica, la publicidad burguesa porlapseudopublicidad del capitalismo avanzado.

La industria cultural de masas desplaza el tipo de publicidad ilustrada, transformándola en consumo y ocio. El ciudadano ya no enriquece el tiempo con el discurso público. La práctica se reduce a pseudoactivismo inducido desde los grandes medios de propaganda de masas que canalizan las pulsiones porvias desublimadoras. Los "sujetos" parecen preferidores racionales pero, su decisión es inducida por los grandes medios. La prensa se desactiva con la noticia inmediata, la composición del mensaje, la ilustración gráfica y los medios audiovisuales. A pesar de su gran capacidad comunicativa, el cine, la radio y la televisión, eliminan la distancia entre ellector reflexivo y el acontecimiento, el receptor es pasivo, no puede reaccionar ante el mensaje.

Según Habermas, Marx había pensado que la publicidad burguesa no podría asumir el acceso de las masas; sería plataforma de cambio social. La transformación de la publicidad burguesa en cultura de masas y del Estado liberal en Estado Social de bienestar, impulsados por el mismo conflicto de clases, ha integrado la lucha de clases en el seno de la nueva dinámica del sistema. El público se ha despolitizado.

El desarrollo democrático del Estado social exige a la posición emancipatoria que las instituciones de la administración y las grandes organizaciones privadas con gran influencia en lo público, sean consideradas parte de la publicidad y, por tanto, controladas democráticamente.

Habermas toma de C.W. Mills la contraposición entre dos tipos de publicidad; en el primero las personas coinciden con el público, existe la posibilidad de réplica, la opinión resultante del debate se convierte en acción y, el público es autónomo respecto a cualquier tutela; en el segundo las personas que pueden expresarse con eficacia se reducen a una minoría sobre una mayoría receptiva y pasiva en la cual los individuos por separado no tienen capacidad de réplica, el paso de la opinión a la actuación es tutelado por las grandes instituciones y, las masas no gozan de autonomia en la formación de la opinión.

Habermas reconoce la centralidad dela democracia en la emancipación humana pero, ignora el problema planteado por Marx; los sujetos que han de llevar adelante la lucha por tales objetivos. Por más que se esté de acuerdo con Habermas en las limitaciones de la clase obrera para "atribuirle", en sentido lukacsiano, la tarea histórica de emancipar a la humanidad, no por ello se tieneque abandonarla ubicación histórico-social de los potenciales emancipatorios; dejar de buscar agentes históricosociales desde los que articular las luchas emancipatorias en la realidad histórica de las diversas opresiones concretas, sus convergencias y contradicciones, sus 
orígenes y culturas. El objetivo a conseguir, la democracia radical, no sabemos como convertirlo en política activa, en praxis histórica. El ciudadano abstracto-participativo que propone carece de historicidad, es político en general, pero no se concretiza en una/s posible/s voluntad/es política/s colectiva/s.

El punto de partida condiciona las virtudes y las limitaciones de la idea de la democracia radical del joven Habermas. Con la teoría crítica de la democracia como participación y la teoría de la formación dialógica del público Habermas ha puesto sólidas bases para una teoría crítica emancipatoria de la democracia, va más allá de los esquemas simplistas y doctrinarios de la tradición marxista de los años sesenta, a la hora de pensar la democracia en las sociedades industriales avanzadas, ya sea en la versión de la dictadura del proletariado o en la versión consejista de la democracia directa, no obstante, en su teoría existe un vacío respecto de los potenciales sujetos históricos de esta alternativa. Los sujetos racionales contrafácticos de su esquema de publicidad burguesa, extendido a toda la ciudadanía, carecen de incardinación en fuerzas históricas prácticas. Praxis dialógica y política activa quedan disociadas. El problema de la praxis se convierte en obstáculo central de su planteamiento. El siguiente trabajo habermasiano se centra en la investigación de este enigma que no se resuelve.

\section{Praxis y democracia}

Habermas toma de $\mathrm{H}$. Arendt la diferenciación entre las concepciones clásica y moderna de praxis. La primera tiene su origen en Aristóteles, la segunda halla su exposición más completa en Hobbes. Aristóteles concibe la costumbre, la ley y la moral en el ámbito de la vida pública. El hombre es un zoon politikon que se realiza como ciudadano ejerciendo la vida pública, guiado por la virtud práctica de la phronesis. Hobbes partiendo de una idea individualista y egoísta de los hombres pretende fundar el orden a partir de un contrato que explique el paso del estado natural -enfrentamiento de todos contra todos- al social, posible, sólo, fundando en este mismo acto el poder absoluto del Estado. Es un modelo técnico de política; elimina los elementos prácticos, pretende explicar causalmente y, utiliza instrumentalmente los conocimientos para realizar el plan preconcebido. Habermas señala la falacia hobbesiana de fundar el estado natural a la manera mecanicista. Tal orientación elude el problema de las normas en un contexto práctico; confunde las leyes de la naturaleza como la "ley natural" normativa. Para realizar el contrato es preciso que se forme un público, es decir, la formación práctica de la política.

Para el joven Hegel, la relación de la filosofía con su realización, de la teoría con la praxis, surge con la reflexión sobre el significado histórico de la Revolución francesa. La Revolución deviene principio de la filosofía de Hegel. La filosofía se ha realizado en la Revolución Francesa; el derecho natural racional se ha convertido en historia. La comprensión filosófica del contrato es el supuesto racional legitimante. Revolución significa que los sujetos sociales y politicos actúan revolucionariamente 
alpretender convertir el derecho natural racional en derecho estatal positivo. El orden revolucionario es legítimo, surge del proceso histórico. La conciencia revolucionaria ha de criticarse porque se pone abstractamente sobre lo particular, es el terror. Del desarrollo histórico surge la necesidad práctica de salvar la contradicción y superar lo que ya es negativo, generando inmanentemente la necesidad; idea e interés coinciden. Si entre la normatividad y la subjetividad se establece la mediación del proceso vital, se realiza la síntesis práctica que mantiene unidos en el proceso lo generaly lo particular. Elderecho abstracto es mediado por la dialéctica de la eticidad.

La teoría reformista del joven Hegel tiene a la revolución como motor en última instancia, por eso, el Hegel conservador de la madurez rechaza esta concepción de la relación teoría y práctica, desactivándola a través de la introducción de los principios delderecho abstracto al margen de la historia; consecuencia del desarrollo del concepto. El poder de lo objetivo que se desenvuelve en la historia no se puede modificar por el hecho de llevarse a concepto, sólo se puede comprender lo que ya es y reconciliar el pensamiento con el ser, legitimando la resignación. Para Habermas, Hegel abdica de la racionalidad práctica en favor del poder. La eticidad es desplazada de la práctica histórica para encarnarse en el Estado.

Habermas ofrece una interpretación filosófica de la Revolución Francesa. En la Asamblea Nacional se realizó una peculiar síntesis de la opinión pública fisiocrática y de la voluntad general de Rousseau que situó a la filosofía en primer plano. Los derechos naturales se fundan en la soberanía popular, no existen en una sociedad civil guiada por leyes "naturales" de intercambio. El poder despótico del soberano es asumido por la voluntad general pero, esta voluntad general no es elconsenso popular rousseauniano, sino la opinión pública ilustrada. Los derechos naturales son derechos políticos. La sociedad es una sociedad política y precisa de la cooperación detodos paramantenerse, es la soberaníapopular en acto. Las doctrinas iusnaturalistas habian dejado irresuelto el paso a la práctica en una sociedad absolutista. La Revolución Francesa ofrecía una solución, la transformación de teoría en praxis; la praxis irrumpe de espaldas a la teoría a través del proceso histórico, adquiriendo realidad el derecho abstracto; es la toma de conciencia activa de los ciudadanos sobre sus propios destinos.

Habermas, siguiendo al joven Hegel, ha desarrollado un concepto de praxis que podría completar sus análisis de la democracia como participación y formación de un público dialógico. Dar este paso requiere seguir el desarrollo del concepto de praxis para la sociedad capitalista. Habermas afronta esta tarea distinguiendo entre los aspectos de la obra marxiana vinculados a: 1) la crítica de la concepción liberal del Estado; 2) la crítica de la filosofla de la historia y; 3 ) la crítica a la obra hegeliana. Sin establecer una relación teórica entre ellos, Habermas critica la fragmentariedad de la teoría de la praxis revolucionaria de Marx y los vacios y saltos que hay entre sus diversos aspectos.

1) Para Habermas, la crítica del Estado liberal marxiana se realiza desde el interior del discurso liberal. Lo quela desvincula de la tradición rousseaunianaque liga 
políticamente los derechos del hombre y del ciudadano. La teoría de la revolución, por lo que hace al Estado, se quedó en esquema estructural de sustitución de la dominación de la burguesía por la dominación del proletariado, al modo de la tradición política moderna -como técnica que adecua medios a un fin, es decir, en razón instrumental-, desligada de laherencia clásica de lapraxis. La democracia concebida prácticamente es ajena a este tipo de razón. Marx, el filósofo de la praxis de las Tesis sobre Feuerbach, no extiende esta consideración a la concepción del Estado y la revolución, le falta una teoría de la democracia constituida prácticamente; los conceptos estratégicos y los prácticos quedan desvinculados.

2) Hegel seculariza la concepción judaica de crisis; piensa la historia como proceso que supera estadios por medio de crisis. El logos, en su desenvolvimiento, con la contradicción -fuerza de negación y síntesis-, conduce la historia hacia la reconciliación. Marx critica la filosofía de la identidad hegeliana como falsa reconciliación, meramente ideal, mientras el mundo está escindido. En la filosofía de la historiamarxiana el concepto de mediación inmanente es interpretado a través de los conceptos de crítica y de crisis en los procesos de producción; crisis económica y lucha de clases. El Espíritu es desplazado como motor de la historia. El sujeto de cambio histórico es la humanidad.

El análisis de la teoría de la crisis del capitalismo deviene piedra angular de esta concepción de praxis. La versión que Habermas ofrece de la teoría del valor es la de plusvalía absoluta, sin incluir elcambio tecnológico y el desarrollo de la productividad, o sea, la plusvalía relativa. Con tal interpretación sesgada, ve el programa marxiano adecuado para elcapitalismo liberal, pero desfasado para el capitalismo desarrollado. Tal conclusión deja la teoría marxiana incapacitada para ayudarnos a comprender el capitalismo tardío. Habemas especula con una serie depseudoconceptos económicos que no desarrolla -"valor perse", "trabajo productivo desegundo orden", o "doble fuente de la plusvalia"-(8) que intentan salvar el vacío existente entre la teoría de la plusvalía absolutay una versión revisada que dé cuenta del capitalismo desarrollado, compatible con el incremento del beneficio y la regulación política de las relaciones de distribución.

La teoría del acceso democrático al gobiemo se convierte en una crítica de la economía politica. Se trata de combinar las tendencias estructurales del capitalismo analizadas por Marx y corregidas por la ley "revisada del valor" con la política keynesiana y las teorías que en los inicios de los años sesenta saltaron a la palestra sobre la sociedad industrial. "Desde esta perspectiva, el conflicto de clases pierde su forma revolucionaria; una democratización progresiva de la sociedad tampoco está excluida de antemano en el marco del orden económico capitalista: una versión del socialismo democrático que, ciertamente, ha aprendido, y también ha conservado, lo suficiente de Marx como para no perder de vista, por encima del desarrollo y aseguramiento del Estado de derecho social, las tendencias opositoras".(9)

3) El esquema hegeliano de la dialéctica del reconocimiento, como anticipación práctica de las limitaciones alienantes, supone la formación práctica del proyecto 
emancipador. Marx aplica esta concepción al proletariado que se constituye en sujeto histórico con la toma de conciencia de clase. La teoría filosófica de la lucha de clases es interpretada en sentido práctico, pero no se relaciona con la formación históricopolitica de la voluntad general, no se relaciona dialéctica y prácticamente con la transformación delEstado, quedando en una abstracción. Una intervención posterior del joven Habermas sobre Marx viene a introducir importantes matices filosóficos al tema de la praxis. Desarrolla al máximo nivel de abstracción un modelo de relación antagónica de las clases fundamentales como dialéctica de la eticidad y supone que Marx cegó este camino; debido a la preeminencia que otorgó de hecho a la categoría instrumental de trabajo, en lugar de la categoría práctica de relaciones de producción.

La categoría hegeliana de la eticidad "es un marco institucional elaborado partiendo de la tradición cultural, pero, precisamente un marco para los procesos de producción".(10) La dialéctica de la eticidad se manifiesta en el conflicto de clases. El conflicto entre partidos opuestos se dirige al control de los medios de producción. "El marco institucional asume también en sí la coacción ejercida por la naturaleza externa, coacción que se expresa en el grado de dominación sobre la naturaleza, en la medida del trabajo socialmente necesario y en la relación existente entre los resarcimientos de que se dispone y las exigencias socialmente desarrolladas; ese marco, mediante la represión de los deseos instintivos, convierte esta coacción en una coacción de la naturaleza interna, y por tanto en una coacción de las normas sociales".(11)

Los intereses de la clase oprimida pugnarán por liberarse de la dominación y ser reconocidos, instaurando una nueva comunidad ética. Este proceso de reconocimiento se enfrenta a la oposición de las clases dominantes que pretenden reforzar su posición. La interpretación habermasiana de la lucha de clases es presentada como un proceso de reflexión y reconocimiento histórico de los macrosujetos clasistas que tiende a la comunidad ética, es decir al dominio de la interacción sobre la instrumentalidad de la razón. Marx no fue consciente de la dimensión implícita en su planteamiento.

Hoy, la relación de clases no puede plantearse bajo esta concepción de la relación de reconocimiento; con el capitalismo desarrollado, se ha integrado la oposición en la síntesis del Estado de bienestar, desplazando el lugar del conflicto del ámbito económico al político. La praxis maxiana es reconducida hacia un programa democrático-reformista que, divisando las fracturas de fondo de la sociedad capitalista y la necesidad de su superación, pueda llevarse a la práctica a través de la formación democrática de la voluntad colectiva lo suficientemente radical y que se atenga al nuevo contexto de crisis, ya no económico, sino político, de regulación y redistribución. El conflicto de clases que surgía de las crisis en Marx es ahora integrado en el programa reformista radical. La crítica de la economía política es desplazada por la crítica del Estado y la regulación. El problema de la praxis, sin embargo, no está resuelto; faltan los sujetos y la eticidad. Los conflictos sociales y los nuevos movimientos de finales de los sesenta y la crisis del capitalismo y del 
Estado de bienestar de los años setenta, llevarán a Habermas a reformular parte de las posiciones a las que ahora ha llegado, desplazando el contexto de crisis del terreno de la política al de la cultura y la legitimación.

\section{Razón instrumental y praxis}

En el contexto del debate intelectual del momento, el joven Habermas entra en la discusión sobre la filosofía de la ciencia. La crítica a la razón instrumental y al cientificismo de la teoría política moderna le llevan a la controversia con el positivismo dominante que niega la vigencia de la crítica y de la emancipación y reduce la praxis a objetivismo y manipulación.

Para Habermas, la racionalidad instrumental del positivismo ha reducido la teoría del conocimiento a teoría de la ciencia, encogiendo el concepto de razón en razón instrumental. Tal tendencia es funcional a las necesidades de crecimiento de las fuerzas productivas bajo el capitalismo, orientadas a dominar la naturaleza y manipular a los humanos. Para el positivismo las ciencias humanas se rigen por el modelo de conocimiento de la física; las relaciones entre acontecimientos de una determinada clase se han de subsumir bajo leyes generales objetivantes. La idea de praxis renovada y el modelo de público dialogante propugnados por Habermas precisan una fundamentación filosófica distinta.

Las disciplinas hermenéuticas, orientadas a la comprensión de los textos de otros, restituidos en su contexto, dirigen su interés a la comprensión mutua, ampliando el ámbito de la intersubjetividad compartida. La orientación de la acción surge de la mayor comprensión entre los participantes, es práctica. El interés de las ciencias naturales estriba en el dominio de la naturaleza; interés técnico. El interés delas disciplinas hermenéuticas pretendefomentar un mayor entendimiento entre los humanos; interés práctico. El primero se realiza históricamente ligado al desarrollo del trabajo, como razón orientada a un fin que dispone medios para realizarlo. EI segundo se realiza a través de la interacción linguistica orientada a la comprensión.

En su origen la teoria crítica pretendia develar las relaciones de dependencia entre los seres humanos y mostrar la representación falsa que estos se hacian de ellas, como sifuesen debidas a lanaturaleza de las cosas y noproductos de la historia susceptibles de ser transformados. La reflexión de los sujetos afectados por estos procesos de alienación permite a los mismos reconocer las posibilidades de emancipación. La autorreflexión crítica de los sujetos destaca el interés emancipatorio.

Los intereses técnico, práctico y emancipativo del conocimiento son el resultado de la evolución de la especie humana y del desarrollo de su historia y median "cuasitrascendentalmente" el conocimiento. Con la teoría de los intereses del conocimiento, la teoría del conocimiento, halla su fundamentación en la teoría social y amplía el concepto de razón que el positivismo ha reducido. Epistemológicamente, halla una vía para replantear el tema de la interacción comunicativa y la praxis, aunque no por 
ello se hayan solventado los problemas políticos en torno a la realización de la praxis anteriormente destacados.

Eljoven Habermas ha esbozado un concepto de razón práctica ampliado desde elque realizar la crítica de la razón instrumental de la modernidad. La argumentación tecnocrática de la ciencia social dominante, pretendidamente neutral, es ideológica; supone un concepto de razón disminuido que elude la praxis democrática y encubre la vigencia de los intereses privados en el desarrollo de las fuerzas productivas bajo el capitalismo.

La defensa de la teoría crítica, desde la razón ampliada, va más allá de los frankfurtianos clásicos. La teoria crítica, impotente ante la expansión de la razón instrumental, como destino inexorable delamodernización quetiende a la cosificación total delas relaciones humanas, con el desarrollo de las categorias deinterés práctico e interés emancipatorio halla una vía de salida; puede ser replanteada desde la concepción ampliada de la racionalidad. La razón instrumental cosificante de la primera teoría crítica está encorsetada en el presupuesto moderno de la relación sujeto-objeto delcual intenta salir de manera impotente a través de las concepciones irracionales de la mimesis y el antisistema. Tampoco se trata de cambiar la racionalidad de la ciencia y de la técnica, como pretendia Marcuse, esto es histórica y estructuralmente imposible. Se trata de desarrollar la interacción comunicativa de manera que confiera al ser humano la capacidad de desarrollar sus posibilidades de interacción reflexivas y libres del dominio ajeno.

Para el joven Habermas, la técnica está ligada al interés técnico de la especie humana, corresponde a una línea histórico-evolutiva que no se puede desandar, es una trama de mediación del ser humano con la naturaleza, plasmada en la relación del trabajo, del cual depende la subsistencia. Lo que es posible es resituar el papel de la razón técnica respecto de la interacción, adoptando una actitud de reconocimiento recíproco entre los humanos que ponga bajo el dominio democrático la razón instrumental; proceso contrario al de servir de coartada ideológica a la dominación capitalista a través de la expansión de las fuerzas productivas.

La interacción es una estructura intersubjetiva de mediación de la acción humana en el proceso evolutivo e histórico de la humanidad-tan fundamental como la acción instrumental ligada al trabajo-. La interacción se desarrolla en el medio simbólico, la comunicación lingüistica cotidiana es su base, constituyendo la intersubjetividad de las expectativas recíprocas institucionalizadas en las cuales se socializan los sujetos humanos, formando su personalidad.

La razón es interpretada en la doble dimensión de la autoproducción material y de la relación social. El materialismo histórico ha de volverse plenamente consciente de la significación filosófica de la interacción -pues ha primado la racionalidad instrumental-. Las relaciones sociales no son explicables por el nivel de desarrollo de las fuerzas productivas, aunque las condicione, son formas prácticas de vida social. La especie humana ha desarrollado fuerzas productivas y las relaciones sociales, la emancipación no puede ser una consecuencia del desarrollo unilateral de las fuerzas 
productivas, depende también de la configuración de las interacciones libres de dominación.

Habermas ha llevado el proceso de reflexión sobre la praxis hasta el umbral de la fundamentación comunicativa, a partir de aquí su proyecto inicia un "cambio de paradigma en filosofía"; el desarrollo de la razón comunicativa requiere abandonar conscientemente la filosofía polarizada en la relación entre el sujeto y el objeto para pasar a una filosofía de la intersubjetividad comunicativa. El proyecto de fundar filosófica y democráticamente la praxis se orienta hacia la pragmática sobre el lenguaje y la teoría de la acción comunicativa -es el proyecto habermasiano de madurez-.

\section{Praxis y capitalismo avanzado}

Weber subsume bajo el concepto de racionalidad los procesos económicos, jurídicos, burocráticos y culturales de la sociedad capitalista. La racionalización de la sociedad depende de la institucionalización del progreso científico y técnico y de su expansión a más dominios de la realidad social, lo cual lleva aparejado el deterioro de las formas tradicionales de vida y las legitimaciones cosmovisionales, provocando un proceso de desencantamiento y secularización. El concepto de razón al que se atienen las nuevas formas de relación es el de la acción racional orientada a fines, en función de los medios a disposición: la razón instrumental desarrollada históricamente.

Para Habermas, en las sociedades capitalistas liberales, las legitimaciones religiosas y metafísicas han perdido globalidad y fuerza. Las funciones de legitimación del sistema económico son realizadas, desde abajo, por el fetichismo espontáneo de la mercancia que presenta al individuo intercambiando equivalentes -la plusvalia no es reconocida-. El sistema económico se autolegitima, es autónomo respecto del Estado. El sistema político liberal depende de la formación de la opinión pública burguesa. Lamotivación social procede, bien de las tradiciones y cosmovisiones aún vigentes $o$, de las ideologías nacidas con las nuevas clases. En suma, en el capitalismo liberal:a) el sistema económico se rige por una racionalidad instrumental, obtener rentabilidad en la inversión privada, dados unos determinados factores económicos; b) el sistema político y la cultura dependen, respectivamente, de la opinión pública, de la tradición y de las ideologías que se generan y mantienen comunicativamente.

En el capitalismo avanzado: 1) El Estado interventor se desarrolla con vistas a estabilizar el sistema económico y evitar las crisis, asegurando el desarrollo y el bienestar. Como consecuencia; repolitiza la sociedad civil, al reintroducir masivamente la decisión estatal en la regulación del mercado; desactiva la legitimación "desde abajo" del capitalismo liberal, acudiendo a la legitimación "desde arriba", a través del sistema de prestaciones sociales; desvincula la discusión pública de la política, sustituida por la eficiencia administrativa. 2) La ciencia y la técnica se 
convierten en la fuerza productiva más importante para el proceso de acumulación. La extensión de la capacidad productiva ofrece compensaciones consumistas a las masas, desactivando el potencial crítico de la sociedad. La nueva forma de dominio institucionalizado, con el desarrollo de la ciencia y de la técnica, "se hace ya irreconocible como dominio político".(12) El Estado y la economía se rigen por la racionalidad instrumental. La razón comunicativa se reduce al mundo de la vida. A medida que la razón instrumental penetre en su ámbito, producirá carencias motivacionales, no regenerables -debido a condicionantes antropológicos y psicológicos-. Habermas replantea el contexto de crisis en el capitalismo desarrollado, la crisis es de motivación y de legitimación. En los trabajos de madurez desarrolla esta tesis.

El esquema de capitalismo avanzado al que llega Habermas ofrece potencialidades críticas que profundizará en sus trabajos de madurez con notable brillantez, no obstante, presenta un esquematismo excesivo que lastra la investigación.

1) Alinterpretar el sistema económico regido, meramente, por la razón instrumental, desconoce las relaciones comunicativas - aunque sean distorsionadas-que nutren el "mundo de vida" económico, así como las relaciones de poder de los individuos y grupos que se dan en su interior. Aceptar la estilización habermasiana implica la denegación de dimensiones irreductibles de la realidad económica, al tiempo que imposibilita la alternativa crítica al sistema económico, excepto en el terreno de la reforma técnica, pero no social ni política. El planteamiento de Habermas acepta como válido el criterio sistémico de la neutralidad político comunicativa del sistema económico, es decir, implícitamente acepta el análisis tecnocrático de la economía, en lugar de destacar la estructura social y política de la acumulación, inscripta en las articulaciones económicas fundamentales desde las cuales el planteamiento crítico-dialéctico cobra verosimilitud y radicalidad.

2) El sistema político también es incluido en los ámbitos que la razón instrumental ha captado y regulado sus articulaciones, desplazando de ellas a la razón comunicativa. En este caso, aunque menos que en el anterior, la estilización de Habermas refleja tendencias reales, pero, el proceso está lejos de haber tenido éxito, puesto que ello es inviable en la medida que la autonomización de la política, convertida en tecnocracia administrativa, no puede eliminar lo político de las relaciones sociales, es decir, el enfrentamiento de puro prestigio de individuos y colectivos sociales que los coloca, indefectiblemente, en situación de lucha por el reconocimiento recíproco, ni la penetración del mundo de la vida en su interior puesto que la administración está compuesta de sujetos que requieren motivación y se relaciona con los ciudadanos a través de la legitimación. La carencia de una comprensión de la política como política activa en Habermas antes destacada se ve agravada por la neutralización implícita para el capitalismo avanzado de la política respecto de lo político. La crítica habermasiana a la política en el capitalismo avanzado será abstracta y la razón práctica quedará recluida a la ética. 


\section{NOTAS}

(1) HABERMAS, J., Perfiles filosófico-politicos, Taurus, Madrid, 1984, pág. 123.

(2) Las obras de los frankfurtianos de la primera generación F. L. Neumann y O. Kircheimer tienen una notable influencia en los planteamientos iniciales de Habermas sobre la democracia, así comola de W. Abendroth, para las obras de los primeros en la teoria politica crítica ver COLOM, F., Las caras del Leviatan, Anthropos, Barcelona, 1992.

(3) HABERMAS, J., "Concepto de participación política", en ABENDROH et al., Capital monopolista y sociedad autoritaria, Fontanella, Barcelona, 1973, pág. 22.

(4) HABERMAS, J., Historia y crítica de la opinión pública, Gustavo Gili, Barcelona, 1981, pág. 84.

(5) Idem, pág. 160.

(6) HABERMAS, J., "La crisis del Estado de bienestar y el agotamiento de las energías utópicas", en Ensayos politicos, Península, Barcelona, 1988.

(7) HABERMAS, J., Historia y ... . op. cit., pág. 173.

(8) HABERMAS, J., Teorla y Praxis, Tecnos, Barcelona, 1987, pág. 248.

(9) Idem, pág. 249.

(10) HABERMAS, J., Conocimiento e interés, Taurus, Madrid, 1982, pág. 68.

(11) Idem, pág. 69.

(12) HABERMAS, J., "Ciencia y técnica como ideologia", en Ciencia y técnica como ideología, Tecnos, Madrid, 1984, pág. 55. 